\title{
Navegando pelos Mares da Discursividade: democracia, políticas públicas e COVID-19
}

\author{
Prezad@s Leitor@s,
}

Esta NAU Social chega carregada de discursividade em seu vigésimo número, décimo primeiro volume, em um momento de forte crise no Brasil, acelerado e ampliado pela chegada da COVID-19. Uma crise que é também moral, pois encontra suas raízes reforçadas na dicotomia e extremismos que temos socialmente construído e tristemente percorrido nos últimos anos. Estes movimentos vêm se mostrando cada vez mais nocivos para a democracia, pois mina muitas de suas essências, como a escuta, a discursividade, a construção respeitosa dos consensos e dissensos e, por fim, a aprendizagem em seu sentido mais amplo. São narrativas de ódio, de separação, de cisão, de preconceitos de todos os tipos, dentre outros absurdos, que encontram justificativa somente naqueles mesmos quadros de valores já contidos nas próprias narrativas, numa retroalimentação aparentemente esvaziada de propósito, que não a propagação de seus próprios conteúdos agressivos. Mas esta estreiteza de propósito se amplia enormemente quando tais narrativas são vistas em conjunto, pois são capazes de naturalizar outras narrativas muito mais perigosas, tais como a da separação entre economia e saúde, mas também a que clama abertamente por um estado de exceção. Por um estado de não democracia e por uma sociedade reprimida em sua discursividade.

A pandemia da COVID-19 exacerba a nossa crise, expõe as nossas feridas sociais, nossas desigualdades, nossa pobreza, nossos altos índices de violência, nosso feminicídio, nossa necropolítica, nosso racismo, nosso elitismo, o medo de nossas instituições, as fragilidades do estado, nossas falências. O que estamos vivendo corremos o risco de nem sabermos exatamente o que é, sua extensão, sua dimensão, sua gravidade, suas consequência. A vida se desmancha, a acumulação de discursividade parece cada vez mais líquida, não dá para não pensar em Bauman, pois seus espaços estão recrudescendo. Somos uma sociedade em disputa. Vivemos narrativas em disputa. Experiências que não se cruzam, que se excluem mutuamente. Há aqueles que disputam por uma volta à normalidade que era, di per se, anormal para uma parcela considerável da nossa sociedade. Ou é normal não ter seus direitos garantidos? Ou é normal não poder lavar as mãos quando necessário? Ou é normal não poder ficar em casa porque não se tem casa? Ou é normal não praticar o isolamento recomendado até mesmo pelo bom senso por falta de condições materiais de sobrevivência? Não, claro que não é, mas muitos e muitos e muitos não podem fazer nenhuma destas coisas porque, simplesmente, não têm condições de fazê-las. É a experiência dolorida, ou mesmo letal, do desamparo público.

O desamparo público parece que repousava na compreensão de que todos os problemas sociais eram consequência direta de uma falta de disponibilidade individual de superação das condições de privação material, também individuais, ou consequência indireta de um mundo globalizado, em constante progresso, em inexorável movimento. Um mundo que não podia parar, cujas trocas materiais, inclusive de corpos humanos com capacidade monetária e social de compra de liberdades para deslocar-se freneticamente, se intensificavam exponencialmente. Mas um mundo que parou. Pararam as chamadas cidades globais, as grandes capitais, as cidades médias, as pequenas, os vilarejos. Até Veneza, na Itália, que nem os teóricos do decrescimento poderiam imaginar, parou - talvez nem Calvino pudesse ter imagino esta cidade invisível, com Marco Polo gondolando pelos canais novamente limpos. Este freio, porém, incomodou rápido demais e a narrativa pela volta ao movimento foi se reorganizando e tomando força, banalizando as perdas de vida humana em detrimento de uma supervalorização das perdas de capital, cujo movimento é fundamental para a sua reprodução. Aqui, começando pelo "Presidente-'E daí?"” do país, expressão eloquente da retórica do desamparo. 
Na contramão do desamparo, o amparo. Mas também a resistência, o respeito, o amor, a solidariedade, a produção de experiências que escutam, acolhem, ampliam, dialogam, constroem. E fazem tudo isto juntos. Um juntos político. Um juntos de uma parte da sociedade que já entendeu que a discursividade é a argumentação em ação. Daquela parte que reconhece e precisa reforçar as narrativas que advogam a noção de sociedade como uma sociedade democrática. Que disputam com as narrativas contrárias. É deste lado da disputa que esta NAU Social está sempre pronta para zarpar, em um movimento de implicação reflexiva e valorativa de quem acredita que fazer ciência é fazer ciência situada, ancorada em seu, em nosso, quadro de valores democráticos, mais ativo do que nunca. E é a partir desta posicionalidade que lançamos mais este número, diante da imensidão de mares que precisamos descobrir, explorar, navegar. Mares como os que agora nos propomos, em nossa pequena contribuição, a adentrar, com nossas bússolas, talvez já desgastadas em sua superfície, mas cada vez mais confiantes no norte que sempre nos apresentou, a democracia, que sempre esteve presente em nossas cartas de navegação.

Assim, diante deste contexto de crise democrática reforçada pela pandemia do novo coronavírus, esta NAU Social decidiu propor um Fórum Especial sobre Democracia, Políticas Públicas e COVID-19, com artigos convidados, por entendermos a urgência deste debate no Brasil e no mundo. A ideia foi termos um conjunto expressivo de textos que refletissem de modo amplo e contundente sobre as relações entre esta atual pandemia e as políticas públicas no país. Buscamos textos que apontassem perguntas, que trouxessem pontos de vista novos, que discutissem nossa sociedade, nosso projeto de desenvolvimento, nossos problemas principais, de natureza social, econômica, política, que se tornaram ainda mais evidentes com esta crise, bem como ilustrassem caminhos possíveis para o que podemos chamar de uma sociedade pós-pandemia, com novas estruturas de argumento, de ação, de quadros de valor, novas formas de solidariedade, novas definições de bens públicos.

Mas antes de apresentarmos uma carta plausível de navegação para tal Fórum, pois muitas são possíveis, como o leitor perceberá, vamos à nossa carta de rotina, com quatro excelentes textos que também dialogam com a temática mais ampla da democracia. Em Novos Territórios, dois artigos nos inspiram: Cotas Raciais em Concursos Públicos e a Perspectiva do Racismo Institucional, escrito por Lucas Mateus Gonçalves Bulhões e Dyego de Oliveira Arruda; e Competências Digitais no Campo de Públicas: a Formação de Gestores Públicos do Século XXI, de autoria de Letícia Dufloth Bianchini, Marco Antônio Almeida Silva, Max Melquíades Silva e Simone Cristina Dufloth. Em Novas Rotas, apresentamos também dois artigos: Políticas Públicas: Subalternidade como Crítica a Racionalidade Linear, dos autores Cássio Henrique Oliveira Conceição e Breitner Luiz Tavares; e Nunca Seremos Desenvolvidos: um Esforço de Desmantelamento da Narrativa Subjacente ao Conceito de Desenvolvimento, de Giselle Alves Silva, Débora C. Paschoal Dourado, Jackeline Amantino de Andrade e Raoni Fernandes Azerêdo.

Passando agora para a nossa segunda carta de navegação, o Fórum Especial sobre Democracia, Políticas Públicas e COVID-19, propomos o desenho de um mapa discursivo formado por alguns mares e muitas águas.

Os primeiros mares são águas mais fortes de reflexão para e sobre a democracia. Nosso ponto de partida sugerido é o texto Pandemia e Política, de Maria Elisabete Pereira dos Santos e Renata Alvarez Rossi, duas vozes que vão buscar na Oran de Albert Camus a inspiração literária para interrogar com precisão a condição pública, construída, da morte desamparada que o estado parece insistir em relegar quem não consegue produzir e reproduzir, individualmente, as condições materiais que the dê alguma dignidade em seu último suspiro, numa negação profunda da espaço público, mas também da própria condição humana. Neste caminho de interrogações complexas, passamos para o texto Entre Pisar Suavemente na Terra ou Comer suas Entranhas: os Desafios que nos Definem como Humanidade, no qual Carla Bronzo, com uma narrativa forte, aponta para a emergência de uma nova revisão paradigmática capaz de acolher a complexidade exigida no enfrentamento dos problemas da vida, como é o caso da crise climática e da desigualdade social, de uma humanidade que parece ainda não ser o que esta autora chama de nosso 
projeto comum. Ampliando estes mares, o texto 0 Comum e a Gestão Social do Pós-pandemia, de Valeria Giannella, nos convida à navegação com um necessário movimento de posicionalidade como fundamento da sua própria crítica, situando sua experiência em termos identitários e reflexivos, em uma importante discussão sobre o comum.

Navegando nos mares ao lado, cada vez mais imersos nas políticas sociais, apresentamos COVID-19 Revela a Desigualdade de Condições da Vida dos Brasileiros, de Aldaiza Sposati, com sua crítica contundente às condições desiguais de resposta à pandemia por uma sociedade tão socialmente excludente como a nossa, na qual uma imensa maioria vê seus riscos de fome e de todo tipo de inadequação crescerem exponencialmente. Ainda nestes mares, A Questão Social Acrescida, de Fernando G. Tenório, com sua lógica afiada, traz de vez a COVID-19 para dentro da questão social, mostrando não somente como esta a amplia, em um contexto social marcado por tantas de suas representações, como é o caso da emergência sanitária, mas também como não se contrapõe à questão econômica. Seguimos pelo estudo exploratório Proteção Social e COVID-19: a resposta do Brasil e das maiores economias da América Latina, no qual Amarílis Busch Tavares, Fabrício Silveira e Rômulo Paes-Sousa avaliam com precisão os conteúdos e o tempo de resposta das principais políticas emergenciais de proteção social editadas pelo governo federal do Brasil, comparando-as com os casos da Argentina, Chile, Colômbia, México e Peru, e apontando com firmeza para a importância na agilidade da edição de tais políticas no alcance da proteção de populações vulneráveis na atual epidemia. As representações da questão social se aprofundam, ainda, com os dois textos seguintes. Em As Condições Objetivas para o Enfrentamento ao COVID-19: Abismo Social Brasileiro, o Racismo, e as Perspectivas de Desenvolvimento Social como Determinantes, Tricia Viviane Lima Calmon põe em xeque a "natureza democrática" desta virose ao olhá-la a partir da perspectiva das condições de resposta por parte da população mais vulnerável, particularmente daqueles que estão em situação de rua e/ou de extrema pobreza. E em A Interiorização da Pandemia: Potenciais Impactos em Populações em Situação de Vulnerabilidade na Amazônia, é a vez de Ana Lúcia Escobar nos levar para uma reflexão situada sobre as condições de expansão da pandemia no norte do país, ressaltando as lacunas de informação, mas também a riqueza das reflexões locais, que apontam para desafios sociais longe de serem confrontados e para os quais a ausência da ação do estado os tornam ainda mais complexos.

Outras águas se anunciam em mares que exploram a discursividade, ainda que em diferentes maneiras. Isaac Reis, em A Retórica da Crise: Democracia e Estabilidade Institucional no Brasil em Tempos da Pandemia de Coronavírus, nos interroga o processo de construção da realidade da pandemia do novo coronavírus, no contexto brasileiro, evidenciando sua dimensão política, bem como seu caráter precário e conflituoso, em um processo de disputas pela produção retórica da crise, entre mídia e autoridades públicas. Fabrício Monteiro Neves, em Provincializando o COVID-19: Resposta ao Vírus em Contexto Hipercomplexo, nos propõe uma nova leitura da pandemia no Brasil, como "província" na sociedade mundial, ao defender que a dinâmica dos nossos sistemas sociais, manifestando-se como expressão de uma complexidade desestruturada e desestruturante, contrariaria o que se poderia esperar de uma suposta centralidade das políticas públicas de saúde mesmo neste momento de pandemia.

Estes últimos movimentos nos levam para novos mares, também contíguos, em cujas águas encontramos que assumem um tom mais propositivo, ou pelo menos apontam saídas. Começamos com Para superar o Divórcio entre Economia e Sociedade: Diagnóstico Crítico e Notas Propositivas em um Contexto de Pandemia, de Genauto Carvalho de França Filho, André Magnelli e Philippe Eynaud, cuja estratégia de superação começa com uma investigação sobre as causas de tal separação, passa para uma reflexão sobre suas consequências em termos ambientais, socioeconômicas e políticas, mas também territoriais e subjetivas, para assumirem, enfim, um tom propositivo em favor de uma retomada da relação entre economia e sociedade, motor de formulação de políticas públicas voltadas para o desenvolvimento solidário de territórios. Seguimos para O Conhecimento Científico como Instrumento Central na Tomada de Decisão na Administração Pública - Sobre a Pandemia de COVID-19 no Brasil, de Tarcísio Marciano 
da Rocha Filho, que discute como vêm sendo tomadas decisões equivocadas e nefastas para o interesse público no país, o que é particularmente crítico neste contexto de pandemia de COVID-19, apontando, no entanto, para importantes dimensões que deveriam orientar o correto relacionamento entre a comunidade científica e os gestores públicos. Com estas reflexões, chegamos no texto de Christiana Soares de Freitas, Camila Luciana Góes Capiberibe e Luísa Martins Barroso Montenegro, Governança Tecnopolítica: Biopoder e Democracia em Tempos de Pandemia, no qual exploram com consistência as convergências entre práticas políticas do biopoder e princípios democráticos em tempos de pandemia da COVID-19, defendendo as possibilidades de aliança entre as práticas biopolíticas e princípios democráticos, em prol do bem-estar público.

Estes mares mais propositivos desembocam nos dois texto finais, cada vez mais perto dos princípios da gestão social. Horácio Nelson Hastenreiter Filho, um dos criadores do recente Observatório da Sociedade Pós-Pandemia, em Um Olhar para a Pandemia a Partir da Perspectiva da Comunicação Governamental, argumenta que a comunicação governamental é um tema importante de debate dentro deste contexto de crise da democracia, apontando alguns caminhos possíveis para a mesma, a partir de uma pesquisa de campo com dados muito recentes e necessários. E, por fim, em Gestão social, Democracia e os Desafios da Crise Sociopolítica no Contexto da Pandemia: uma Análise a partir da RGS e do ENAPEGS 2020, Leonardo Prates Leal e Maria Amélia Jundurian Corá apresentam suas reflexões sobre como as incertezas deste momento estão impactando a gestão social como um campo de pesquisa, como uma prática no contexto da RGS, e como está impactando a organização do Encontro Nacional de Pesquisadores em Gestão Social (ENAPEGS), apresentando ainda criativas oportunidades para que, mesmo em tempos tão complicados como este, caminhemos na consolidação do campo epistemológico e tecnológico da gestão social.

Com estas cartas de navegação, agradecendo aos autores e felizes com a produção discursiva deste número, convidamos você a embarcar conosco nesta NAU Social, reforçando juntos os propósitos de ampliar nossas estruturas narrativas e experiências de reflexividade pública na busca por uma sociedade mais democrática e mais justa com os diferentes públicos que nos conforma.

Boa navegação e leitura a todos!

Um cordial abraço, muito obrigado e sigamos juntos aprendendo,

\section{Revista NAU Social}

Rosana Boullosa, editora-chefe

Ives Tavares, editor executivo 